\title{
Validity and Test-Retest Reliability of the Dutch Modified Perceived Deficits Questionnaire to Examine Cognitive Symptoms in Women with Chronic Whiplash, Chronic Idiopathic Neck Pain, and Fibromyalgia
}

Citation for published version (APA):

Lenoir, D., De Pauw, R., Ickmans, K., Schumacher, C., Timmers, I., Kregel, J., \& Coppieters, I. (2018). Validity and Test-Retest Reliability of the Dutch Modified Perceived Deficits Questionnaire to Examine Cognitive Symptoms in Women with Chronic Whiplash, Chronic Idiopathic Neck Pain, and Fibromyalgia. Pain Practice, 18(7), 850-863. https://doi.org/10.1111/papr.12683

Document status and date:

Published: 01/09/2018

DOI:

10.1111/papr.12683

Document Version:

Publisher's PDF, also known as Version of record

Document license:

Taverne

Please check the document version of this publication:

- A submitted manuscript is the version of the article upon submission and before peer-review. There can be important differences between the submitted version and the official published version of record. People interested in the research are advised to contact the author for the final version of the publication, or visit the DOI to the publisher's website.

- The final author version and the galley proof are versions of the publication after peer review.

- The final published version features the final layout of the paper including the volume, issue and page numbers.

Link to publication

\footnotetext{
General rights rights.

- You may freely distribute the URL identifying the publication in the public portal. please follow below link for the End User Agreement:

www.umlib.nl/taverne-license

Take down policy

If you believe that this document breaches copyright please contact us at:

repository@maastrichtuniversity.nl

providing details and we will investigate your claim.
}

Copyright and moral rights for the publications made accessible in the public portal are retained by the authors and/or other copyright owners and it is a condition of accessing publications that users recognise and abide by the legal requirements associated with these

- Users may download and print one copy of any publication from the public portal for the purpose of private study or research.

- You may not further distribute the material or use it for any profit-making activity or commercial gain

If the publication is distributed under the terms of Article $25 \mathrm{fa}$ of the Dutch Copyright Act, indicated by the "Taverne" license above,

Download date: 26 Apr. 2023 


\section{ORIGINAL ARTICLE}

\section{Validity and Test-Retest Reliability of the Dutch Modified Perceived Deficits Questionnaire to Examine Cognitive Symptoms in Women with Chronic Whiplash, Chronic Idiopathic Neck Pain, and Fibromyalgia}

D. Lenoir, MSc, PT ${ }^{*}$; R. De Pauw, MSc, PT, MT*; K. Ickmans, PhD, PT ${ }^{\dagger, \neq}$; C. Schumacher, MSc, PT*; I. Timmers, PhD ${ }^{\mathbb{S}, \text { II}}$; J. Kregel, MSc*,+‡; I. Coppieters, $\mathrm{MSc}, \mathrm{PT}^{*}, \dagger$

"Department of Rehabilitation Sciences and Physiotherapy, Faculty of Medicine and Health Sciences, Ghent University, Ghent, Belgium; ${ }^{\dagger}$ Pain in Motion International Research Group;

${ }^{\ddagger}$ Department of Physiotherapy, Human Physiology and Anatomy (KIMA), Faculty of Physical Education \& Physiotherapy, Vrije Universiteit Brussels, Brussels, Belgium; ${ }^{\circledR}$ Department of Cognitive Neuroscience, Maastricht University, Maastricht, The Netherlands; ${ }^{\mathbb{I}}$ Department of Rehabilitation Medicine, Maastricht University, Maastricht, The Netherlands

\section{Abstract}

Introduction: Until now, only reliability and validity of the English version of the modified Perceived Deficits Questionnaire (mPDQ) have been investigated.

Objective: The aim of this study was to translate the MPDQ into Dutch and evaluate its validity and reliability as an assessment tool for self-perceived cognitive problems in patients with chronic whiplash-associated disorders (CWAD), chronic idiopathic neck pain (CINP), and fibromyalgia (FM). Methods: A case-control study was performed with a volunteer sample of 13 women with CWAD, 18 with CINP,

Address correspondence and reprint requests to: Dorine Lenoir, MSc, PT, Rehabilitation Sciences and Physiotherapy Ghent Campus Heymans (UZ) 3 B3, De Pintelaan 185, Ghent, Belgium. E-mail: dorine.lenoir@ ugent.be.

Submitted: April 25, 2017; Revision accepted: January 23, 2018 DOI. 10.1111/papr.12683

C 2018 World Institute of Pain, 1530-7085/18/\$15.00

Pain Practice, Volume 18, Issue 7, 2018 850-863 and 33 with FM, and 33 women who were healthy and free of pain. The $\mathrm{mPDQ}$ was first translated into Dutch, and its testretest reliability, internal consistency, and discriminative power were examined.

Results: The intraclass correlation coefficients were higher than 0.74 . Cronbach's $\alpha$ values ranged between 0.71 and 0.95 . Total mPDQ scores were significantly higher $(P<0.017)$ in FM and CWAD patients compared to healthy controls. Furthermore, participants performed the Stroop task and the psychomotor vigilance task (PVT), 2 neuropsychological computer-based cognitive performance tests. Correlations between the MPDQ total score and the cognitive performance tests were evaluated. Significant moderate to high correlations were found in all study samples between total mPDQ score and objective cognitive tests (Spearman correlation coefficient $=0.35$ to $0.80 ; P<0.05$ ).

Conclusion: Therefore, the Dutch version of the mPDQ showed high test-retest reliability and high internal consistency, and was able to distinguish CWAD and FM patients from healthy controls. 
Perspective: This article presents the validity and test-retest reliability of the Dutch $\mathrm{mPDQ}$. This measure could help clinicians who seek a reliable and user-friendly way to assess cognitive symptoms in chronic pain patients.

Key Words: cognition disorders, chronic pain, validation studies, surveys and questionnaires

\section{INTRODUCTION}

Besides persisting pain, patients with chronic neck pain often report cognitive symptoms, such as memory and concentrations deficits. ${ }^{1}$ In fibromyalgia (FM), cognitive impairments in patients might be more disabling than their experienced pain. $^{2}$ Therefore, assessment of cognitive symptoms is an important part in the evaluation of cognitive disabilities, in order to compose an effective therapy for these chronic pain patients. Consequently, different tools are available for the assessment of cognitive deficits.

First, cognitive performance can be assessed using performance-based neuropsychological tests, potentially computer-based, performed by clinicians or patients., There is a broad choice of tests that measure cognitive performance in chronic pain patients. Some frequently used tests are the Mini-Mental State Examination, clock drawing test, paced auditory serial addition task, operation span task, as well as the Stroop task and the psychomotor vigilance task (PVT). ${ }^{2,5,6}$ The Stroop task and PVT have been used in previous studies to investigate objective cognitive performance in chronic pain patients in general, and in chronic whiplash patients and FM patients in specific. ${ }^{3,4}$ Each of these tests evaluates certain aspects of cognitive functioning (ie, the Stroop task for selective attention and cognitive control, and the PVT for vigilance and alertness). ${ }^{7}$ The validity and reliability of these tests have already been evaluated and have shown positive outcomes. ${ }^{8-12}$ The Stroop task has been evaluated in various populations, ranging from patients with traumatic brain injuries, to patients with Alzheimer's disease, attention-deficit/hyperactivity disorder, and vascular dementia. ${ }^{13-18}$ The PVT, on the other hand, has mainly been investigated in the context of the impact of sleep deprivation on vigilant attention. ${ }^{10-12,19}$

Second, questionnaires can be used to assess selfperceived cognitive problems. Since these usually take up less time and equipment for completion, they are of interest in the evaluation of patients. For example, the Perceived Deficits Questionnaire (PDQ) is a tool to evaluate cognitive functioning based on the subjective report of a patient. ${ }^{20}$ It was originally developed for use in patients with multiple sclerosis but has subsequently been used to evaluate cognitive symptoms among patients with other conditions as well (ie, patients with chronic whiplash-associated disorders [CWAD]). ${ }^{21}$ Compared to other questionnaires assessing levels of perceived cognitive symptoms, such as the Subjective Cognitive Impairment Scale or the Cognitive Failures Questionnaire, the PDQ is of particular interest because it includes a broad range of cognitive domains but is concise at the same time. ${ }^{22-28}$ It consists of 4 different subcategories concerning different cognitive functions, namely attention and concentration, retrospective memory, prospective memory, and organization and planning. Clinical usefulness of the English PDQ was demonstrated by Sullivan et al. ${ }^{22}$ in a preliminary study in patients with acute and chronic whiplash. Its validity and reliability were investigated by Takasaki et al. ${ }^{20}$ in a sample of people with CWAD, which showed that 2 of the included items did not fit within the construct of the questionnaire. Since these items formed a threat to the unidimensionality, they were eliminated from their relevant sections, resulting in the modified PDQ (mPDQ). Calculation of internal consistency in each section of the mPDQ showed acceptable results. The test-retest reliability for each subcategory of both the original and modified PDQs was considered acceptable for people with CWAD.

Currently, no valid and reliable Dutch version of the mPDQ is available for the evaluation of self-reported cognitive functioning in native Dutch-speaking persons with chronic pain. Such a health questionnaire is a feasible and indispensable tool for therapeutic and research purposes to evaluate (progress in) self-reported cognitive functioning. However, the outcomes of a research instrument and the meaning of its composition of components may vary from one culture to another. ${ }^{29}$ In order to study the medical needs of people with diverse cultural backgrounds, research instruments must be evaluated on reliability and validity in each culture for which they are composed. Therefore, it is important to watch over the quality of the translation and ensure adequate validation of the translated instrument. In this way only is it possible to ensure that the results obtained from the questionnaire are not due to errors in translation, but rather a result of the presence of real differences in the studied matter. ${ }^{30}$

Subsequently, the current study aimed to (1) examine the validity of the Dutch translation of the mPDQ by 
assessing the convergent validity, internal consistency, and discriminative power of the questionnaire and its correlations with neuropsychological cognitive tests in a sample of patients with CWAD, chronic idiopathic nontraumatic neck pain (CINP), and FM; and (2) assess the test-retest reliability of the Dutch version of the mPDQ.

\section{METHODS}

\section{Study Design and Setting}

The present case-control study took place at the Department of Rehabilitation Sciences and Physiotherapy of Ghent University, Ghent, Belgium. Participants received detailed oral and written study information and gave written informed consent prior to study participation. All patients and healthy control participants were unpaid volunteers. This research was approved by the Ethics committee of Ghent University Hospital (reference number 2015/1233).

\section{Participants and Assessments}

Three patient populations were chosen that often report cognitive disorders in the clinical practice and that show some similar characteristics. Whiplash and FM patients both show central sensitization on the group level, whereas whiplash and CINP patients share the neck as an important source of pain. The fact that these populations have important similarities but still distinguish themselves from each other based on other characteristics made this comparison a very interesting one in our opinion.

The study was performed from February 2016 until October 2016. All participants were recruited by means of flyers, posters, and a call on the website for scientific research of the University of Ghent. The flyers and posters were distributed in rehabilitation centers, private physiotherapy practices, primary care facilities (general practitioners and pharmacists), and companies with workers prone to computer work on a daily basis. All participants were native Dutch-speaking women between 18 and 65 years of age.

The study sample consisted of 13 CWAD patients, 18 CINP patients, 33 FM patients, and 33 healthy pain-free women. For inclusion, CWAD patients had to be classified as having WAD type II or III, based on the modified Quebec Task Force Classification. ${ }^{31,32}$ CINP patients had to experience chronic neck pain and dysfunction on the day of testing that had been present for a minimal time span of 3 months with a mean pain intensity higher than 4 out of 10 on a numeric pain rating scale. FM patients had to be diagnosed following the criteria as stated by the American College of Rheumatology in 2010. ${ }^{33}$ FM patients with a history of a whiplash trauma and CWAD patients who also met the diagnostic criteria for FM were excluded. Healthy pain-free women were excluded if they had experienced pain or discomfort in the past year for a period longer than 8 consecutive days with a pain intensity higher than 2 out of 10 on a numeric pain rating scale. Pregnant women and women up to 1 year postnatal were excluded to minimize the odds for confounding factors. Furthermore, all participants were asked to stop analgesics of step 1 of the World Health Organization ladder (http://www.who.int/cancer/palliative/painladder/en/) 48 hours prior to study participation. Their treating physicians were informed and had to approve the discontinuation of the medication. Moreover, to be included, all patients had to have a stable medication intake during the 4 weeks prior to study participation. However, if a patient took pain medication, such as antidepressants or soft or strong opioids, continuation of intake was permitted, since intake of these medications cannot be abruptly interrupted.

Lastly, all participants were asked not to undertake heavy physical exertion, and to refrain from consuming alcohol, caffeine, and nicotine on the day of the experiments.

\section{Development of the Dutch Modified Perceived Deficit Questionnaire}

Multiple methods have been recommended to achieve a representative version of a questionnaire in a different language. One of them is the principle of forward translation, meaning that the English version was translated into Dutch. ${ }^{34}$ In this translation, 3 independent researchers from Ghent University were involved. They were all familiar with the terminology of the area covered by the instrument and with interview skills. The researchers had a C1 level of English, but their mother tongue was Dutch. Additionally, 2 native Dutch-speaking persons with master's degrees in English, but without knowledge of the specific terminology, made an independent forward translation of the same questionnaire. The 5 independent translations were compared, and after discussing the differences during a consensus meeting, the final version of the Dutch mPDQ 
questionnaire was constructed. This is also known as the committee approach. ${ }^{30}$

This result was then given to an independent pilot group of 15 women with CINP, 15 with CWAD, and 15 healthy native Dutch-speaking women. They were asked to fill out the questionnaire and to point out unclear words or sentence constructions. No ambiguities were indicated, and therefore no changes were made to the translation.

\section{Cognitive Performance Testing}

Procedure. On the day of testing $\left(\mathrm{T}_{0}\right)$, all study participants started by completing a digital version of the Dutch mPDQ to assess self-reported cognitive deficits. Next, cognitive performance was assessed in a more objective way by using a battery of 2 consecutive performance-based computer tasks. These were completed in a fixed order (ie, first the Stroop task followed by the PVT). At the end, all patients performed the Rey 15 memory test.

Two weeks later $\left(T_{1}\right)$, the mPDQ was sent by e-mail to all participants for a second online completion in order to examine test-retest reliability. All participants were instructed to complete the questionnaire on day 14 after the first completion.

Dutch mPDQ - The mPDQ contains 18 questions concerning self-perceived cognitive problems to be rated on a 5-point Likert scale anchored from never (0) to almost always (4). Higher scores are indicative of more cognitive deficits (range 0 to 72 ). ${ }^{20}$ These 18 questions belong to 4 different subcategories, namely attention and concentration (4 items), retrospective memory (4 items), prospective memory (5 items), and organization and planning (5 items).

Research has already shown that the English mPDQ is clinically useful ${ }^{22}$ and has indicated acceptable internal consistency in the questionnaire, together with good convergent validity and high test-retest reliability $(0.79 \leq$ intraclass correlation coefficient $[$ ICC $] \leq 0.83) .{ }^{20}$ Therefore, the English mPDQ has been labeled as a valid and reliable tool in the assessment of cognitive problems and the monitoring of recovery.

The Stroop task - The Stroop task has been validated as a tool to evaluate selective attention and choice reaction time. ${ }^{9}$ This test shows high test-retest reliability $(0.71 \leq$ ICC $\leq 0.88)$ and only small learning effects. ${ }^{8}$ In this task, participants were shown words that were written in different ink colors. The instruction was to press a button with the color consistent with the ink color, as fast as possible. Three different conditions were used, namely, "congruent" (word and ink color refer to the same color), "incongruent" (word and ink color are different), and "neutral" (display of neutral words in a certain color of ink). ${ }^{3,6}$ The Stroop task has been used and described in detail in our previous studies on females with chronic fatigue syndrome ${ }^{7,35}$ and chronic WAD. ${ }^{4,6}$ Mean response reaction times and accuracy for each of these 3 conditions for correct responses were taken into account for further analyses (Stroop reaction time congruent, incongruent, and neutral, and Stroop accuracy congruent, incongruent, and neutral). Higher reaction times and lower accuracy represent worse outcome.

The psychomotor vigilance task - The PVT has been validated as a measure of sustained attention, alertness, and simple reaction time. ${ }^{10}$ The task is based on a simple visual reaction time test apparatus originally developed by Wilkinson and Houghton. ${ }^{36}$ Participants were instructed to respond as quickly as possible to a visual stimulus (red spot on a black screen) presented at a variable time interval (2 to 10 milliseconds). The trial was saved as a lapse, if a response had not been made within 500 milliseconds. The PVT reaction time of correct responses and the amount of lapses were registered and used for statistical analyses. Longer reaction times and higher amount of lapses are an indication of worse sustained attention. Again, the PVT has been used and described in detail in our previous studies on females with chronic fatigue syndrome $e^{7,35}$ and chronic WAD. ${ }^{4,6}$

The test has shown good test-retest reliability for median response times (ICC $=0.89, P<0.0001$ ) and number of PVT lapses $(\mathrm{ICC}=0.83, P<0.0001) .{ }^{11}$ Convergent validity of the test has been evaluated positively. ${ }^{12,37-40}$

The Rey 15 memory test - Malingering is the phenomenon of exaggeration in symptom presentation. It was defined in 1999 as "volitional exaggeration or fabrication of cognitive dysfunction for the purpose of obtaining substantial material gain, or avoiding or escaping formal duty or responsibility." 41

The Rey 15 memory test is frequently used to detect this malingering. ${ }^{42,43}$ This test can be administered under the condition that the participant is not mentally weak or is not suffering from mental deterioration. ${ }^{44}$ It 
is a readily available test with easy administration and low cost. During this test, a visual representation of an array of 15 mostly related items is given to the participant. The participant is given 10 seconds to study the array and is then asked to reproduce it with paper and pencil. For each reproduction of a correct item, the participant is awarded a score of 1 . A cut-off of 7 of 15 was used to distinguish malingerers from nonmalingerers. ${ }^{45}$ During this test, there are actually only 5 data that need to be retained, since reproduction of the remaining 10 items should be assured by the mechanisms of associations and automatisms. Therefore, scores below the cut-off are indicative of exaggeration and doubtful collaboration. ${ }^{44}$ Since the Rey 15 memory test cannot be used as a stand-alone test to conclude on malingering, positive scores should be further investigated. The test has been validated in a population with brain damage and has been proven to show an excellent specificity. ${ }^{43,46,47}$

\section{Statistical Analysis}

First, normality of variables was checked using the Shapiro-Wilk test and by visual evaluation of QQ-plots and histograms. Additionally, equality of variance was examined with Levene's test. Results of these analyses combined with rather small sample sizes in the CWAD and CINP groups led to the application of nonparametric testing.

The process to achieve a reliable and valid questionnaire consists of full psychometric testing. ${ }^{34}$ According to recommendations and common use, the following analyses were carried out: (1) calculation of test-retest reliability, (2) internal consistency, (3) discriminative power, and (4) convergent construct validity. All statistical analyses were carried out using IBM $^{\circledR}$ SPSS ${ }^{\circledR}$ Statistics 22.0 (IBM Corp., Armonk, NY, U.S.A.).

1. Comparison of the results of the mPDQ on the testing day $\left(\mathrm{T}_{0}\right)$ relative to the result 14 days later $\left(T_{1}\right)$ was used to evaluate test-retest reliability. Differences in results can be caused by real changes or by imperfections of the questionnaire. In case of a perfect evaluation tool, all differences should be caused by real changes. To evaluate this, an ICC was calculated. The ICC lies between 0 and 1 , where a value of 0 indicates no test-retest reliability and a value of 1 symbolizes perfect testretest reliability. Values lower than 0.40 represent poor test-retest reliability, values of 0.40 to 0.75 are labeled as being average to good, and above 0.75 , excellent test-retest reliability is achieved. ${ }^{48}$

2. Based on the results at $T_{0}$, Cronbach's $\alpha$ was calculated to evaluate the internal consistency of the questionnaire. The closer this value is to 1 , the more the variance is caused by true variance and the lower the within-subject variability is. Therefore, a high Cronbach's $\alpha$ value is a sign of a valid questionnaire.

3. To evaluate if the outcome of the mPDQ can distinguish healthy pain-free controls from CINP, CWAD, and FM patients, the discriminative power of the questionnaire was evaluated. Because of small sample sizes in the CINP and CWAD groups, nonparametric testing was performed. A Kruskal-Wallis test was applied with post-hoc pairwise comparisons, using the MannWhitney $U$ test to examine the capacity of the questionnaire to distinguish between healthy controls and the patient groups. Since the outcomes of the healthy controls were compared to 3 patient groups, the significance level was set at 0.017 after Bonferroni correction (0.05/3).

4. Calculation of correlations between the outcomes of the MPDQ and objective cognitive performance tests was used to evaluate the convergent construct validity of the mPDQ. The calculation of correlations between the mPDQ total score and the performance-based cognitive test items was performed by calculating the Spearman correlation coefficient. The significance level was set at 0.05 and the rule of thumb was applied for interpreting the size of the correlation coefficients whereby correlation coefficients of 0.30 to 0.50 are low, 0.50 to 0.70 are moderate, 0.70 to 0.90 are high, and 0.90 to 1.00 are very high. ${ }^{49}$

5. Additionally, an examination was made of the differences in (opioid and nonopioid) pain medication intake between the different groups. The evaluation of significant differences in intake between the groups was done with a chi-square test for opioid medication and Fisher's exact test for nonopioid medication that were evaluated at a significance level of 0.05 .

\section{RESULTS}

Descriptives of the included study sample can be found in Table 1. 
Table 1. Descriptives of Age, Weight, Height, BMI, and mPDQ Total

\begin{tabular}{|c|c|c|c|c|c|c|}
\hline Variable & Population & Median & Interquartile Range & Range (minimum-maximum) & Test Statistic ( $P$ value) & $P$ value Post-Hoc \\
\hline \multirow[t]{4}{*}{ Age (years)* } & Healthy & 25.0 & 21.3 to 32.5 & 18.0 to 53.0 & $20.845(<0.001)$ & $0.002^{\dagger}$ \\
\hline & CINP & 47.0 & 36.0 to 52.0 & 18.0 to 62.0 & & $<0.001$ \\
\hline & FM & 43.0 & 29.3 to 51.8 & 24.0 to 59.0 & & $0.005^{\S}$ \\
\hline & CWAD & 40.0 & 29.5 to 52.0 & 21.0 to 65.0 & & \\
\hline \multirow[t]{4}{*}{ Weight $(\mathrm{kg})^{*}$} & Healthy controls & 61.0 & 55.5 to 66.0 & 48.0 to 78.0 & $8.579(0.035)$ & $0.593^{\dagger}$ \\
\hline & CINP & 61.5 & 57.0 to 67.8 & 50.0 to 75.0 & & 0.006 \\
\hline & FM & 68.0 & 60.0 to 80.0 & 45.0 to 94.0 & & $0.671^{\S}$ \\
\hline & CWAD & 62.0 & 55.0 to 71.5 & 48.5 to 99.0 & & \\
\hline \multirow[t]{4}{*}{ Height $(\mathrm{cm})^{*}$} & CINP & 168.0 & 160.5 to 172.0 & 160.0 to 180.0 & $2.149(0.542)$ & NA \\
\hline & FM & 167.0 & 163.0 to 169.0 & 149.0 to 176.0 & & \\
\hline & Healthy controls & 168.0 & 161.8 to 171.0 & 155.0 to 178.0 & & \\
\hline & CWAD & 165.0 & 160.0 to 167.8 & 156.0 to 173.0 & & \\
\hline \multirow[t]{4}{*}{ BMI $\left(\mathrm{kg} / \mathrm{m}^{2}\right)^{*}$} & Healthy controls & 21.9 & 20.8 to 22.9 & 17.01 to 26.84 & $10.449(0.015)$ & $0.851^{\dagger}$ \\
\hline & CINP & 22.0 & 19.9 to 23.6 & 19.05 to 28.23 & & 0.002 \\
\hline & FM & 24.2 & 21.7 to 28.0 & 16.81 to 35.38 & & $0.338^{\S}$ \\
\hline & CWAD & 22.7 & 19.9 to 27.2 & 19.72 to 34.26 & & \\
\hline \multirow[t]{5}{*}{ mPDQ total $(/ 72)^{*}$} & Healthy controls & 12.0 & 6.5 to 17.5 & 0.0 to 30.0 & $34.142(<0.001)$ & $0.021^{\dagger}$ \\
\hline & CINP & 17.5 & 12.0 to 25.8 & 1.0 to 46.0 & & $<0.001^{+}$ \\
\hline & FM & 28.0 & 20.5 to 39.0 & 10.0 to 56.0 & & $<0.001^{\S}$ \\
\hline & CWAD & 29.0 & 17.5 to 39.0 & 4.0 to 44.0 & & \\
\hline & \multicolumn{6}{|c|}{$\begin{array}{l}\text { Frequencies (Respectively higher education; higher } \\
\text { secondary education; lower secondary education) }\end{array}$} \\
\hline \multirow[t]{4}{*}{ Education level, $n(\%)^{\natural}$} & \multicolumn{2}{|c|}{ Healthy } & \multicolumn{2}{|c|}{21 (63.6); 9 (27.3); $0(0)$} & $3.847(0.707)$ & NA \\
\hline & \multicolumn{2}{|c|}{ CINP } & \multicolumn{2}{|c|}{10 (55.6); 7 (38.9); 1 (5.6) } & & \\
\hline & \multicolumn{2}{|c|}{ FM } & \multicolumn{2}{|c|}{20 (60.6); 10 (30.3); 3 (9.1) } & & \\
\hline & \multicolumn{2}{|c|}{ CWAD } & \multicolumn{2}{|c|}{7 (63.6); $3(27.3) ; 0(0)$} & & \\
\hline
\end{tabular}

Significant values are represented in bold. The population consisted of 33 healthy controls, 18 CINP patients, 33 FM patients, and 13 CWAD patients.

* Because of non-normality of distribution of the data and small sample sizes for CINP and CWAD, all data were analyzed using the Kruskal-Wallis test and the Mann-Whitney $U$ test for post-hoc pairwise comparisons. To correct for multiple comparisons, differences measured with the Mann-Whitney $U$ test were only deemed significant below the 0.017 level (Bonferonni correction: $0.05 / 3$ ). ${ }^{\dagger} P$ value for significant differences between healthy controls, CINP. ${ }^{\ddagger} P$ value for significant differences between healthy controls, FM. ${ }^{\S} P$ value for significant differences between healthy controls, CWAD. 'Categorical data were analyzed via Fisher's exact test. BMI, body mass index; mPDQ, modified Perceived Deficits Questionnaire; CINP, chronic idiopathic nontraumatic neck pain; FM, fibromyalgia; CWAD, chronic whiplash-associated disorders; NA, not applicable.

\section{Psychometric Testing mPDQ}

1. Statistical analysis for test-retest reliability of the mPDQ led to the results that are shown in Table 2. For this analysis, results from 2 testing moments were compared. Six participants did not fill out the questionnaire a second time, leading to a response rate of $93.8 \%$. The ICC was higher than 0.75 for all the components of the questionnaire $(0.79$ to 0.95$)$ in healthy controls, as well as in patients with CINP or FM. This indicates an excellent test-retest reliability, meaning that the results at $\mathrm{T}_{0}$ were mostly parallel to the results 14 days later $\left(T_{1}\right)$. In participants with WAD, the ICC for attention and concentration achieved a value of 0.74 , indicating good test-retest reliability. Outcomes of the ICC for the other components of the mPDQ were higher than 0.75 in this study sample as well (0.85 to 0.87), indicating excellent test-retest reliability for these items.

2. The analysis examining the internal consistency, based on Cronbach's $\alpha$, showed that all values ranged between 0.71 and 0.95 . This was the lowest for prospective memory in FM patients and the highest for prospective memory in healthy controls. This outcome indicates that about $70 \%$ to $90 \%$ of the variance is a result of true and reliable variance (Table 3).

3. For the evaluation of the discriminative power of the questionnaire, results of the total mPDQ score were compared between the healthy controls and different patient groups. The Kruskal-Wallis test showed a significant difference between the groups $(\mathrm{H}(3)=34.14, P<0.001)$. Post-hoc pairwise comparisons using the Mann-Whitney $U$ test showed that significant higher values in outcome on total mPDQ score were found between healthy controls and women with CWAD $(\mathrm{U}=126.50, P<0.001)$ and FM $(\mathrm{U}=66.50, P<0.001)$. There was no significant difference between healthy controls and women with $\operatorname{CINP}(\mathrm{U}=180.50, P=0.02)$.

\section{Correlations Between mPDQ and Performance-Based Cognitive Test Items}

The calculation of Spearman correlation coefficients between total mPDQ score on the one hand and PVT 
Table 2. Test-Retest Reliability of the MPDQ in CWAD, FM, and CINP Patients, and in Healthy Controls

\begin{tabular}{|c|c|c|c|}
\hline Variable & Population & $\begin{array}{l}\text { ICC (average } \\
\text { measure) }\end{array}$ & $\begin{array}{l}\text { ICC } 95 \% \\
\text { Confidence } \\
\text { Interval }\end{array}$ \\
\hline \multirow{4}{*}{$\begin{array}{l}\text { mPDQ, attention } \\
\text { and concentration }\end{array}$} & Healthy controls & 0.789 & 0.562 to 0.898 \\
\hline & CINP & 0.871 & 0.616 to 0.957 \\
\hline & FM & 0.832 & 0.651 to 0.919 \\
\hline & CWAD & 0.739 & 0.143 to 0.920 \\
\hline \multirow{4}{*}{$\begin{array}{l}\text { mPDQ, retrospective } \\
\text { memory }\end{array}$} & Healthy controls & 0.941 & 0.877 to 0.971 \\
\hline & CINP & 0.853 & 0.563 to 0.951 \\
\hline & FM & 0.885 & 0.762 to 0.945 \\
\hline & CWAD & 0.867 & 0.564 to 0.959 \\
\hline \multirow{4}{*}{$\begin{array}{l}\text { mPDQ, prospective } \\
\text { memory }\end{array}$} & Healthy controls & 0.814 & 0.614 to 0.910 \\
\hline & CINP & 0.947 & 0.890 to 0.974 \\
\hline & $\mathrm{FM}$ & 0.930 & 0.791 to 0.976 \\
\hline & CWAD & 0.870 & 0.574 to 0.960 \\
\hline \multirow{4}{*}{$\begin{array}{l}\text { mPDQ, organization } \\
\text { and planning }\end{array}$} & Healthy controls & 0.924 & 0.842 to 0.963 \\
\hline & CINP & 0.908 & 0.725 to 0.969 \\
\hline & FM & 0.913 & 0.819 to 0.958 \\
\hline & CWAD & 0.846 & 0.494 to 0.953 \\
\hline \multirow[t]{4}{*}{ mPDQ, total score } & Healthy controls & 0.946 & 0.889 to 0.974 \\
\hline & CINP & 0.930 & 0.790 to 0.976 \\
\hline & FM & 0.906 & 0.806 to 0.955 \\
\hline & CWAD & 0.868 & 0.566 to 0.960 \\
\hline
\end{tabular}

ICC, intraclass correlation coefficient; mPDQ, modified Perceived Deficits Questionnaire; CINP, chronic idiopathic nontraumatic neck pain; FM, fibromyalgia; CWAD, chronic whiplash-associated disorders.

Table 3. Internal Consistency of the MPDQ in CWAD, FM, and CINP Patients, and in Healthy Controls

\begin{tabular}{llc}
\hline Variable & Population & Cronbach's $\alpha$ \\
\hline mPDQ, attention and concentration & Healthy controls & 0.789 \\
& CINP & 0.871 \\
& FM & 0.832 \\
mPDQ, retrospective memory & CWAD & 0.739 \\
& Healthy controls & 0.941 \\
& CINP & 0.853 \\
mPDQ, prospective memory & FM & 0.885 \\
& CWAD & 0.867 \\
& Healthy controls & 0.709 \\
mPDQ, organization and planning & CINP & 0.947 \\
& FM & 0.930 \\
& CWAD & 0.870 \\
& ClNPalthy controls & 0.924 \\
mPDQ, total score & FM & 0.908 \\
& CWAD & 0.913 \\
& Healthy controls & 0.846 \\
& CINP & 0.946 \\
& FM & 0.930 \\
& CWAD & 0.906 \\
& & 0.868
\end{tabular}

mPDQ, modified Perceived Deficits Questionnaire; CINP, chronic idiopathic nontraumatic neck pain; FM, fibromyalgia; CWAD, chronic whiplash-associated disorders.

and Stroop task on the other hand showed positive correlations for the following outcomes: PVT reaction time, PVT lapses, Stroop reaction time congruent, Stroop reaction time incongruent, and Stroop reaction time neutral. For the CINP sample, these correlations were moderate to high, ranging between 0.624 and
0.799. In the FM sample, low positive correlations were only found between total mPDQ score and PVT reaction time, Stroop reaction time incongruent, and Stroop reaction time neutral (correlation coefficients $=0.486$, 0.350 , and 0.374 , respectively). Lastly, in the CWAD sample, moderate to high positive correlations were found between total mPDQ score and PVT reaction time, Stroop reaction time congruent, and Stroop reaction time incongruent (correlation coefficients $=0.702,0.558$, and 0.619). Positive correlations indicate that high outcomes on the MPDQ are related to high outcomes on (some conditions of) the objective tests and vice versa. These results can be found in Table 4.

Significant differences $(P<0.05)$ between the different study samples in performance-based cognitive test results were determined by performing a Kruskal-Wallis test with post-hoc pairwise comparisons using the Mann-Whitney $U$ test. Significant differences between healthy controls on the one hand and CWAD and FM patients on the other hand were found for the following test items: PVT reaction time, PVT lapses, Stroop reaction time congruent, Stroop reaction time incongruent, and Stroop reaction time neutral. For the CINP sample, significant differences with healthy controls could only be found in the test item PVT lapses. These results can be found in Table 5 .

Analysis of the Rey 15 memory test showed that 2 participants of the patient sample demonstrated malingering. A score of $6 / 15$ was achieved by 1 person with FM and 1 healthy control. A Kruskal-Wallis test was performed to examine significant differences in outcome on the Rey 15 memory test between the study samples but did not show significant outcomes $(P \geq 0.05)$.

\section{Differences in Medication Intake}

Since differences in opioid medication intake between the groups could form an important cause of confounding factors, an evaluation was made of the differences in this intake between the different groups. The use of opioids was present in 5\% of the CINP patients, in $6 \%$ of the FM patients, and in $0 \%$ of the CWAD patients. Healthy controls were not included in this analysis since a difference in medication intake between healthy controls and the patient populations is obvious.

The outcomes of the chi-square test, represented in Table 6, show that no significant differences in opioid medication intake could be found between the different groups. $47.4 \%$ of CINP patients used nonopioid pain 
Table 4. Spearman Correlations Between mPDQ and PVT and Stroop Test

\begin{tabular}{|c|c|c|c|c|}
\hline & Variable & Population & $\begin{array}{l}\text { Spearman } \\
\text { Correlation }\end{array}$ & $\begin{array}{l}\text { Significance } \\
\text { (2-Tailed) }\end{array}$ \\
\hline \multirow[t]{8}{*}{ PVT } & \multirow[t]{4}{*}{ PVT RT } & Healthy controls & -0.185 & 0.310 \\
\hline & & CINP & 0.624 & 0.006 \\
\hline & & FM & 0.486 & 0.005 \\
\hline & & CWAD & 0.702 & 0.008 \\
\hline & \multirow[t]{4}{*}{ PVT lapses } & Healthy controls & 0.090 & 0.622 \\
\hline & & CINP & 0.644 & 0.005 \\
\hline & & FM & 0.274 & 0.129 \\
\hline & & CWAD & 0.362 & 0.224 \\
\hline \multirow{24}{*}{$\begin{array}{l}\text { Stroop } \\
\text { task }\end{array}$} & \multirow{4}{*}{$\begin{array}{l}\text { Stroop RT } \\
\text { congruent }\end{array}$} & Healthy controls & 0.064 & 0.728 \\
\hline & & CINP & 0.690 & 0.002 \\
\hline & & $\mathrm{FM}$ & 0.345 & 0.053 \\
\hline & & CWAD & 0.558 & 0.047 \\
\hline & \multirow{4}{*}{$\begin{array}{l}\text { Stroop RT } \\
\text { incongruent }\end{array}$} & Healthy controls & -0.104 & 0.572 \\
\hline & & CINP & 0.799 & $<0.001$ \\
\hline & & FM & 0.350 & 0.049 \\
\hline & & CWAD & 0.619 & 0.024 \\
\hline & \multirow{4}{*}{$\begin{array}{c}\text { Stroop RT } \\
\text { neutral }\end{array}$} & Healthy controls & 0.084 & 0.648 \\
\hline & & CINP & 0.676 & 0.003 \\
\hline & & FM & 0.374 & 0.035 \\
\hline & & CWAD & 0.459 & 0.114 \\
\hline & \multirow{4}{*}{$\begin{array}{l}\text { Stroop Acc } \\
\text { congruent }\end{array}$} & Healthy controls & -0.193 & 0.289 \\
\hline & & CINP & 0.354 & 0.163 \\
\hline & & FM & 0.031 & 0.868 \\
\hline & & CWAD & 0.437 & 0.135 \\
\hline & \multirow{4}{*}{$\begin{array}{l}\text { Stroop Acc } \\
\text { incongruent }\end{array}$} & Healthy controls & 0.006 & 0.974 \\
\hline & & CINP & -0.085 & 0.746 \\
\hline & & FM & -0.253 & 0.163 \\
\hline & & CWAD & -0.433 & 0.140 \\
\hline & \multirow{4}{*}{$\begin{array}{c}\text { Stroop Acc } \\
\text { neutral }\end{array}$} & Healthy controls & 0.062 & 0.734 \\
\hline & & CINP & 0.085 & 0.746 \\
\hline & & FM & 0.105 & 0.569 \\
\hline & & CWAD & 0.464 & 0.111 \\
\hline
\end{tabular}

Significant values are represented in bold $(P<0.05)$. The population consisted of 33 healthy controls, 18 CINP patients, 33 FM patients, and 13 CWAD patients.

PVT, psychomotor vigilance task; RT, reaction time; Acc, accuracy; mPDQ, modified

Perceived Deficits Questionnaire; CINP, chronic idiopathic nontraumatic neck pain; FM,

fibromyalgia; CWAD, chronic whiplash-associated disorders.

medication, compared to $61.5 \%$ of the CWAD patients and $63.3 \%$ of the FM patients.

Differences in nonopioid medication intake were evaluated as well, by use of Fisher's exact test, and were found to be nonsignificant as well. The outcomes of this analysis are also presented in Table 6.

\section{DISCUSSION}

Since research has repeatedly shown the presence of cognitive symptoms in women with CWAD, CINP, and FM, the purpose of this study was to evaluate the validity and reliability of the Dutch translation of the mPDQ regarding the assessment of cognitive functioning. ${ }^{2,3,6,50}$ Many different questionnaires exist for the evaluation of these symptoms.

Questionnaires such as the Illness Perception Questionnaire, Subjective Cognitive Impairment Scale, and Cognitive Failures Questionnaire are already used in the
Table 5. Kruskal-Wallis Test with Post-Hoc Pairwise Comparisons Using the Mann-Whitney $U$ Test on Objective Cognitive Tests

\begin{tabular}{|c|c|c|c|c|}
\hline & Variable & Population & $\begin{array}{l}\text { Test Statistic } \\
\text { ( } P \text { Value) }\end{array}$ & $\begin{array}{l}P \text { Value } \\
\text { Post-Hoc }\end{array}$ \\
\hline \multirow[t]{2}{*}{ PVT } & PVT RT & $\begin{array}{l}\text { Healthy controls } \\
\text { CINP } \\
\text { FM } \\
\text { CWAD }\end{array}$ & $19.415(<0.001)$ & $\begin{array}{l}0.176^{\star} \\
<0.001^{\dagger} \\
0.002^{\ddagger}\end{array}$ \\
\hline & PVT lapses & $\begin{array}{l}\text { Healthy controls } \\
\text { CINP } \\
\text { FM } \\
\text { CWAD }\end{array}$ & $20.099(<0.001)$ & $\begin{array}{l}0.003^{*} \\
<0.001^{\dagger} \\
0.001^{\dagger}\end{array}$ \\
\hline \multirow[t]{6}{*}{$\begin{array}{l}\text { Stroop } \\
\text { task }\end{array}$} & $\begin{array}{l}\text { Stroop RT } \\
\text { congruent }\end{array}$ & $\begin{array}{l}\text { Healthy controls } \\
\text { CINP } \\
\text { FM } \\
\text { CWAD }\end{array}$ & $22.933(<0.001)$ & $\begin{array}{l}0.027^{*} \\
<0.001^{\dagger} \\
0.001^{\star}\end{array}$ \\
\hline & $\begin{array}{l}\text { Stroop RT } \\
\text { incongruent }\end{array}$ & $\begin{array}{l}\text { Healthy controls } \\
\text { CINP } \\
\text { FM } \\
\text { CWAD }\end{array}$ & $19.971(<0.001)$ & $\begin{array}{l}0.046^{*} \\
<0.001^{\dagger} \\
0.001^{\dagger}\end{array}$ \\
\hline & $\begin{array}{l}\text { Stroop RT } \\
\text { neutral }\end{array}$ & $\begin{array}{l}\text { Healthy controls } \\
\text { CINP } \\
\text { FM } \\
\text { CWAD }\end{array}$ & $19.779(<0.001)$ & $\begin{array}{l}0.085^{*} \\
<0.001^{\dagger} \\
0.004^{\dagger}\end{array}$ \\
\hline & $\begin{array}{l}\text { Stroop Acc } \\
\text { congruent }\end{array}$ & $\begin{array}{l}\text { Healthy controls } \\
\text { CINP } \\
\text { FM } \\
\text { CWAD }\end{array}$ & $4.905(0.179)$ & NA \\
\hline & $\begin{array}{l}\text { Stroop Acc } \\
\text { incongruent }\end{array}$ & $\begin{array}{l}\text { Healthy controls } \\
\text { CINP } \\
\text { FM } \\
\text { CWAD }\end{array}$ & $3.159(0.368)$ & NA \\
\hline & $\begin{array}{c}\text { Stroop Acc } \\
\text { neutral }\end{array}$ & $\begin{array}{l}\text { Healthy controls } \\
\text { CINP } \\
\text { FM } \\
\text { CWAD }\end{array}$ & $2.827(0.419)$ & NA \\
\hline
\end{tabular}

Significant values are represented in bold $(P<0.05)$. The population consisted of 33 healthy controls, 18 CINP patients, 33 FM patients, and 13 CWAD patients.

${ }^{\star} P$ value for significant differences between healthy controls, CINP. ${ }^{\dagger} P$ value for significant differences between healthy controls, FM. ${ }^{\ddagger} P$ value for significant differences between healthy controls, CWAD. PVT, psychomotor vigilance task; RT, reaction time; Acc, accuracy; CINP, chronic idiopathic nontraumatic neck pain; FM,

fibromyalgia; CWAD, chronic whiplash-associated disorders. NA, not applicable.

context of evaluating cognitive symptoms. However, questionnaires such as the Illness Perception Questionnaire evaluate a specific aspect of cognition that can influence pain experience, whereas the MPDQ evaluates cognition in a broad but concise and structured way. ${ }^{51}$ This questionnaire moreover evaluates cognition in all its aspects without focusing on specific functions.

Making such a questionnaire that evaluates cognition in all its aspects without focusing on specific functions is hard if you want to keep it manageable, but in our opinion, the mPDQ was a good attempt at it. Since the English mPDQ evaluates a broad range of cognitive domains in a brief and comprehensive way and it has already been validated in patients with CWAD, the choice to use this specific questionnaire was made. The results of the present study showed high test-retest reliability and internal consistency of the questionnaire. 
Table 6. Chi-Square Test for Medication Intake

\begin{tabular}{lccc}
\hline & $\begin{array}{l}\text { Opioid } \\
\text { Medication } \\
\text { Intake }\end{array}$ & & $\begin{array}{l}\text { Nonopioid } \\
\text { Medication } \\
\text { Intake }\end{array}$ \\
\hline Pearson chi-square value & 1.370 & Fishers exact test & 1.316 \\
$\begin{array}{l}\text { Asymptotic } \\
\text { significance (2-sided) }\end{array}$ & 0.504 & $\begin{array}{l}\text { Exact significance } \\
\text { (2-sided) }\end{array}$ & 0.529 \\
\hline
\end{tabular}

The population consisted of 18 chronic idiopathic neck pain (CINP) patients, 33 fibromyalgia (FM) patients, and 13 chronic whiplash-associated disorder (CWAD) patients. Opioid medication intake: CINP: 5\%; FM: 6\%; CWAD: 0\%. Nonopioid medication intake: CINP: 47.4\%; CWAD: 61.5\%; FM: 63.3\%.

These results are similar to the findings described by Takasaki et al. ${ }^{20}$ in their evaluation of the English version of the mPDQ, which was to be expected if the translation was well performed. The results of the discriminative power analysis showed that the $\mathrm{mPDQ}$ can distinguish healthy controls from CWAD and FM patients based on self-reported cognitive problems. Previous research showed correlations in these patient groups between subjective evaluations of cognitive functioning and objective cognitive tests. ${ }^{3,50}$ Therefore, the hypothesis was formed that outcomes on the mPDQ would correlate with the outcomes on the Stroop task and PVT. However, the findings concerning correlations between our performance-based cognitive tests and the mPDQ were more diverse. PVT reaction time, PVT lapses, and Stroop congruent, incongruent, and neutral reaction times showed significant positive correlations with the mPDQ total score, indicating that the experience of subjective cognitive problems coincided with objective cognitive deficits. These correlations were observed in every included study sample, and were highest in patients with CINP. The fact that these outcomes are more diverse is not a surprising finding since other research has shown discrepancies between outcomes on self-reported measurements on the one hand and objective tests in patients with chronic pain on the other hand. ${ }^{52-55}$ These disagreements in the literature can be explained by the large variety of objective and cognitive tests that can be used for the assessment of cognitive functioning. The choice of using the Stroop task and PVT was made since these were used in previous studies with similar populations..$^{2-4,6}$ However, many other different cognitive tests exist to evaluate cognitive functioning in chronic pain patients. Moreover, this also shows that a questionnaire will always remain a subjective, self-reported way of assessing symptoms.

Of all study participants, the CINP sample experienced the least number objective cognitive deficits.
Only for the test item PVT lapses could a significant difference in outcome compared to healthy controls be observed. This outcome is more or less in line with previous research that has shown that, based on the Trail Making Test, CINP patients do not show objective cognitive problems when compared to healthy controls. ${ }^{56}$ Nevertheless, this is an interesting finding since other studies have shown that these patients do experience objective cognitive disorders. ${ }^{50}$ These differences in findings could be explained by the use of different tools for the assessment of cognitive complaints. Moreover, a significant difference in age was found between our study populations. Therefore, this needs to be taken into account when interpreting the differences in these outcomes between the included populations.

\section{Study Limitations and Strengths}

When interpreting the results, the following study limitations have to be taken into account. Firstly, the study sample consisted of 13 CWAD patients, 18 CINP patients, 33 FM patients, and 33 healthy controls. Since there was a smaller sample size for CWAD and CINP patients, a lack of power could lead to the possibility of occurrence of type 2 errors. Post-hoc power analysis showed that the power of the findings was sufficiently high for 6 of the 8 used variables. The power was insufficient for the Stroop accuracy congruent and Stroop accuracy incongruent condition. These are also the conditions for which no significant results were found. However, the inability to find significant results could be a result of a lack of power.

Moreover, only women were included for this study, which impacts the generalizability of our findings. Secondly, in the general instruction section of the $\mathrm{mPDQ}$, it is stated that "everyone experiences problems with memory, attention, or concentration at some point, but these problems may occur more frequently for individuals with chronic pain, such as whiplash." Since this is stated in this way in the original version, it was correspondingly translated into Dutch. This can be seen as an insinuation that could lead to a certain bias while completing the questionnaire. However, since this was also the case in the original validation study of the English version, this does not result in additional adverse results on the validity and reliability of the Dutch mPDQ.

Thirdly, findings from Kruskal-Wallis testing with post-hoc pairwise comparisons using the Mann- 
Whitney $U$ test showed that there is a significant difference in age between the different sample groups. This is an important finding since age can have an influence on cognition. ${ }^{57,58}$ The distribution of age showed a younger population in the group of included healthy controls when compared to the other patient groups. However, since nonparametric testing was performed, the results of the statistical analyses were not corrected for age. Since age can have an influence on the performance of objective cognitive tests, it is important to keep this limitation in mind when evaluating the results.

Despite the above-mentioned limitations, several strengths of this study can be outlined. Firstly, the translation of a questionnaire is not a straightforward process. Therefore, different protocols were followed in order to obtain a valid translation. All these methods, however, have their strengths and their weaknesses.

In a translation process, a bilingual phase is often used. However, in order to execute this phase of translation, it was necessary to give both Dutch and English versions of the questionnaire to a bilingual pretest group. The difficulty with this procedure, however, is that a response bias can be caused by recall of one's previous answers. ${ }^{30}$ To avoid this, enough time should be provided between the completion of both questionnaires, but the person's situation should stay the same. Since this is extremely difficult to accomplish, Cronbach's $\alpha$ was chosen to evaluate the internal consistency of the questionnaire.

Concerning the forward translation, the choice of the translators was a strength. All translators were researchers who were familiar with the subject and were fluent in English. Secondly, by adding 2 translators with an English master's degree, the probability for a bias was minimalized during the committee approach. ${ }^{30} \mathrm{We}$ decided to only perform forward translation, without backward translation. This choice was made since the use of back-translation may have an influence on the initial forward translation. ${ }^{59}$ As a result, the style of the translation may be rather artificial since the researcher might keep the future backward translation in mind while performing the forward translation. Moreover, the expectation to obtain a seemingly identical version to the original after a backward translation is in conflict with the fact that translation requires change, adaptation, and compromise.

The translation of the questionnaire was based on the study by Takasaki et al., ${ }^{20}$ reviewing the original PDQ. In their study, the mPDQ contains statements instead of questions, whereas we decided to use questions. We made this choice because most of the other health questionnaires that are currently in use contain questions as well.

Thirdly, before administering the questionnaire to the patient sample, a pilot study was performed in an independent sample with similar characteristics. ${ }^{60}$ The participants in this pilot testing consisted of 15 healthy controls, 15 CINP patients, and 15 CWAD patients. They fulfilled the same inclusion and exclusion criteria as the participants in the final study.

Lastly, the risk for confounding factors was decreased in 2 ways. Firstly, the prevalence of malingering in postwhiplash patients is a frequently seen phenomenon. This is particularly of importance in situations in which the patient is involved in litigation contexts. By checking for low outcomes on the Rey 15 memory test, the influence of malingering on the outcomes was examined. Statistical analysis showed that outcomes from participants in the patient samples did not differ from the ones of healthy controls. The low values, seen in 2 participants, can possibly be attributed to a wrong understanding of the instructions. Unfortunately, data on involvement in litigation contexts was not collected at the moment of data collection. Therefore, we cannot investigate the possible link between outcomes and litigation on the one hand or the relationship between malingering and litigation on the other hand. These would have been interesting analyses.

Secondly, differences in intake of (non-)opioid medication between the groups can also influence the results. However, in our statistical analyses, we found that there was no significant difference in opioid or nonopioid medication intake between the different patient groups. Therefore, we can exclude this as being a possible confounding factor.

\section{Recommendations for Further Research and Clinical Practice}

The sample sizes for CWAD and CINP patients were rather small in this study. Therefore, further research could investigate if research with larger sample sizes results in similar findings. Moreover, further research should aim to obtain age-controlled groups, to exclude the possible influence of differences in age on differences in outcome. The inclusion of patients with other types of chronic pain in the research sample could be of interest as well in order to generalize the conclusion to a larger population. 
With these results, we can state that the Dutch mPDQ is a valid tool to assess cognitive functioning. However, research on the causal relation between chronic neck pain and cognitive symptoms is currently lacking. It has already been hypothesized that pain may influence cognitive symptoms because neural systems involved in cognition and pain processing are closely linked. ${ }^{61,62} \mathrm{In}$ this way, they may modulate one another reciprocally. Therefore, it would be interesting to evaluate if the impact of pain on cognition can be shown in the results on the mPDQ.

In addition, examining the link between the cognitive symptoms and other symptoms observed in patients with chronic pain would be a relevant next step. For example, sleeping problems have already frequently been described as being a common problem in chronic pain patients. ${ }^{63,64}$ The relationship between pain and these sleeping problems, as well as the influence of therapy on sleep and pain, have already been investigated. Moreover, the impact of sleep deprivation on cognitive functioning in healthy workers has already been investigated as well. ${ }^{65}$ However, the relationship between sleep deprivation and cognitive problems in chronic pain patients is still unclear. More research is needed to determine if there is a causal relationship between both.

As mentioned in the Discussion section, examining the link between involvement in litigation contexts and cognitive symptoms could be an interesting aspect to include in future research within these chronic pain populations.

The validity of the Dutch mPDQ is relevant in clinical practice because it is a practical tool for the evaluation of self-reported cognitive symptoms. Its use should also be considered to evaluate progress in therapeutic settings, for example, as a part of follow-up measurements.

\section{CONCLUSION}

The results of the present study demonstrate excellent test-retest reliability and internal consistency of the Dutch version of the MPDQ, a self-report tool to assess perceived cognitive problems. Determination of the discriminative power of the MPDQ showed that the questionnaire can distinguish healthy pain-free controls from CWAD and FM patients in terms of their self-reported cognitive problems. Correlations between more performance-based cognitive tests and the total mPDQ score showed that more objectively measured problems with reaction time, concentration, and memory were correlated with increased self-reported cognitive problems with attention, concentration, memory, organization, and planning. These correlations were the strongest in CINP patients, but were also found in women with FM and CWAD to a certain extent. Accordingly, all these findings together provide evidence for the validity and reliability of the Dutch mPDQ. We therefore advise using the Dutch mPDQ in research and clinical practice as a simple and userfriendly tool to assess cognitive deficits in women with CINP, FM, and CWAD.

\section{ACKNOWLEDGEMENTS}

The authors gratefully acknowledge the participants of this study, without whom this study could have never been completed successfully. We also want to thank Mira Meeus for scientific advice and critical review of the study proposal.

\section{DISCLOSURES}

D.L. is a PhD research fellow funded by Fonds Wetenschappelijk Onderzoek (FWO). I.C. is a $\mathrm{PhD}$ research fellow funded by the Special Research Fund of Ghent University (BOF-Ghent; BOF13/DOC/276). J.K. is a $\mathrm{PhD}$ research fellow funded by the Agency for Innovation by Science and Technology (IWT), Applied Biomedical Research Program (TBM), Belgium. K.I. is a postdoctoral research fellow funded by the Agency for Innovation by Science and Technology (IWT), Applied Biomedical Research Program (TBM), Belgium. The authors declare that no conflicts of interest exist.

\section{FUNDING SOURCES}

This work was supported by the Special Research Fund of Ghent University (BOF-Ghent, BOF13/DOC/276).

\section{REFERENCES}

1. Kim JM, Hong JP, Kim SD, Kang HJ, Lee YS. Development of a Korean version of the perceived deficits questionnaire-depression for patients with major depressive disorder. Clinical Clin Psychopharmacol Neurosci. 2016;14: 26-32.

2. Bertolucci PH, de Oliveira FF. Cognitive impairment in fibromyalgia. Curr Pain Headache Rep. 2013;17:344.

3. Coppieters I, Ickmans K, Cagnie B, et al. Cognitive performance is related to central sensitization and health- 
related quality of life in patients with chronic whiplashassociated disorders and fibromyalgia. Pain Phys. 2015;18: E389-E401.

4. Ickmans K, Meeus M, De Kooning M, et al. Exercise and cognitive functioning in people with chronic whiplashassociated disorders: a controlled laboratory study. J Orthop Sports Phys Ther. 2016;46:87-95.

5. Sjogren $\mathrm{P}$, Thomsen AB, Olsen AK. Impaired neuropsychological performance in chronic nonmalignant pain patients receiving long-term oral opioid therapy. J Pain Symptom Manage. 2000;19:100-108.

6. Meeus M, Van Oosterwijck J, Ickmans K, et al. Interrelationships between pain processing, cortisol and cognitive performance in chronic whiplash-associated disorders. Clin Rheumatol. 2015;34:545-553.

7. Ickmans K, Meeus M, Kos D, et al. Cognitive performance is of clinical importance, but is unrelated to pain severity in women with chronic fatigue syndrome. Clin Rheumatol. 2013;32:1475-1485.

8. Jensen AR, Rohwer WD Jr. The Stroop color-word test: a review. Acta Physiol (Oxf). 1966;25:36-93.

9. MacLeod CM. Half a century of research on the Stroop effect: an integrative review. Psychol Bull. 1991;109: 163-203.

10. Lim J, Dinges DF. Sleep deprivation and vigilant attention. Ann N Y Acad Sci. 2008;1129:305-322.

11. Dorrian J, Rogers N, Dinges DF Psychomotor vigilance performance: neurocognitive assay sensitive to sleep loss. In: Kushida CA, ed. Sleep Deprivation: Clinical Issues, Pharmacology and Sleep Loss Effects. New York: Marcel Dekker; 2005: 39-70.

12. Wyatt JK, Cajochen C, Ritz-De Cecco A, Czeisler CA, Dijk DJ. Low-dose repeated caffeine administration for circadian-phase-dependent performance degradation during extended wakefulness. Sleep. 2004;27:374-381.

13. Rabin LA, Barr WB, Burton LA. Assessment practices of clinical neuropsychologists in the United States and Canada: a survey of INS, NAN, and APA Division 40 members. Arch Clin Neuropsychol. 2005;20:33-65.

14. Ponsford J, Kinsella G. Attentional deficits following closed-head injury. J Clin Exp Neuropsychol. 1992;14:822838 .

15. Dikmen SS, Machamer JE, Winn HR, Temkin NR. Neuropsychological outcome at 1-year post head injury. Neuropsychology. 1995;9:80-90.

16. Spieler DH, Balota DA, Faust ME. Stroop performance in healthy younger and older adults and in individuals with dementia of the Alzheimer's type. J Exp Psychol Hum Percept Perform. 1996;22:461-479.

17. Nigg JT, Blaskey LG, Huang-Pollock CL, Rappley MD. Neuropsychological executive functions and DSM-IV ADHD subtypes. I Am Acad Child Adolesc Psychiatry. 2002;41:59-66.

18. Boyle PA, Paul RH, Moser DJ, Cohen RA. Executive impairments predict functional declines in vascular dementia. Clin Neuropsychol. 2004;18:75-82.
19. Dinges DF, Powell JW. Microcomputer analyses of performance on a portable, simple visual RT task during sustained operations. Behav Res Methods Instrum Comput. 1985; 17:652-655.

20. Takasaki H, Chien CW, Johnston V, Treleaven J, Jull G. Validity and reliability of the perceived deficit questionnaire to assess cognitive symptoms in people with chronic whiplashassociated disorders. Arch Phys Med Rehabil. 2012;93:17741781.

21. Fehnel SE, Forsyth BH, DiBenedetti DB, Danchenko N, Francois C, Brevig T. Patient-centered assessment of cognitive symptoms of depression. CNS Spectr. 2016;21:4352.

22. Sullivan MJ, Hall E, Bartolacci R, Sullivan ME, Adams H. Perceived cognitive deficits, emotional distress and disability following whiplash injury. Pain Res Manag. 2002;7:120 126.

23. Edgley KSM, Dehoux E. A survey of multiple sclerosis, Part 2: determination of employment status. Can J Rehab. 1991;4:127-132.

24. Woods SP, Carey CL, Moran LM, Dawson MS, Letendre SL, Grant I. Frequency and predictors of self-reported prospective memory complaints in individuals infected with HIV. Arch Clin Neuropsychol. 2007;22:187-195.

25. Woods SP, Iudicello JE, Moran LM, Carey CL, Dawson MS, Grant I. HIV-associated prospective memory impairment increases risk of dependence in everyday functioning. Neuropsychology. 2008;22:110-117.

26. Cuttler C, Graf P, Pawluski JL, Galea LA. Everyday life memory deficits in pregnant women. Can J Exp Psychol. 2011;65:27-37.

27. Moller JT, Cluitmans P, Rasmussen LS, et al. Longterm postoperative cognitive dysfunction in the elderly ISPOCD1 study. ISPOCD investigators. International Study of Post-Operative Cognitive Dysfunction. Lancet. 1998;351: $857-861$.

28. Chang WC, Chan TC, Chiu SS, et al. Self-perceived cognitive functioning and its relationship with objective performance in first-episode schizophrenia: the Subjective Cognitive Impairment Scale. Compr Psychiatry. 2015;56:4250 .

29. Munet-Vilaro F, Egan M. Reliability issues of the family environment scale for cross-cultural research. Nurs Res. 1990;39:244-247.

30. Maneesriwongul W, Dixon JK. Instrument translation process: a methods review. J Adv Nurs. 2004;48:175186.

31. Spitzer WO, Skovron ML, Salmi LR, et al. Scientific monograph of the Quebec Task Force on Whiplash-Associated Disorders: redefining "whiplash" and its management. Spine. 1995;20(8 Suppl):1s-73s.

32. Sterling M. A proposed new classification system for whiplash associated disorders-implications for assessment and management. Man Ther. 2004;9:60-70.

33. Wolfe F, Clauw DJ, Fitzcharles MA, et al. The American College of Rheumatology preliminary diagnostic criteria 
for fibromyalgia and measurement of symptom severity. Arthritis Care Res (Hoboken). 2010;62:600-610.

34. Sousa VD, Rojjanasrirat W. Translation, adaptation and validation of instruments or scales for use in cross-cultural health care research: a clear and user-friendly guideline. J Eval Clin Pract. 2011;17:268-274.

35. Ickmans K, Clarys P, Nijs J, et al. Association between cognitive performance, physical fitness, and physical activity level in women with chronic fatigue syndrome. J Rehabil Res Dev. 2013;50:795-810.

36. Wilkinson RT, Houghton D. Field test of arousal: a portable reaction timer with data storage. Hum Factors. 1982;24:487-493.

37. Wesensten NJ, Belenky G, Thorne DR, Kautz MA, Balkin TJ. Modafinil vs. caffeine: effects on fatigue during sleep deprivation. Aviat Space Environ Med. 2004;75:520 525 .

38. Van Dongen HP, Dinges DF. Investigating the interaction between the homeostatic and circadian processes of sleep-wake regulation for the prediction of waking neurobehavioural performance. J Sleep Res. 2003;12:181-187.

39. Jewett ME, Dijk DJ, Kronauer RE, Dinges DF. Doseresponse relationship between sleep duration and human psychomotor vigilance and subjective alertness. Sleep. 1999;22:171-179.

40. Doran SM, Van Dongen HP, Dinges DF. Sustained attention performance during sleep deprivation: evidence of state instability. Arch Ital Biol. 2001;139:253-267.

41. Slick DJ, Sherman EM, Iverson GL. Diagnostic criteria for malingered neurocognitive dysfunction: proposed standards for clinical practice and research. Clin Neuropsychol. 1999;13:545-561.

42. Slick DJ, Tan JE, Strauss EH, Hultsch DF. Detecting malingering: a survey of experts' practices. Arch Clin Neuropsychol. 2004;19:465-473.

43. Reznek L. The Rey 15-item memory test for malingering: a meta-analysis. Brain Inj. 2005;19:539-543.

44. Frederick R. A review of Rey's strategies for detecting malingered neuropsychological impairment. J Forensic Neuropsychol.2008;2:3-4, 1-25.

45. Lee GPL, David W, Martin RC. Rey's 15-item visual memory test for the detection of malingering: normative observations on patients with neurological disorders. Psychol Assess. 1992;4:43-46.

46. Bernard LC, Fowler W. Assessing the validity of memory complaints: performance of brain-damaged and normal individuals on Rey's task to detect malingering. J Clin Psychol. 1990;46:432-436.

47. Goldberg JO, Miller HR. Performance of psychiatric inpatients and intellectually deficient individuals on a task that assesses the validity of memory complaints. J Clin Psychol. 1986;42:792-795.

48. Health measurement scales: a practical guide to their development and use (5th edition). Aust N Z J Public Health. 2016;40:294-295.
49. Mukaka MM. Statistics corner: a guide to appropriate use of correlation coefficient in medical research. Malawi Med J. 2012;24:69-71.

50. Thompson DP, Urmston M, Oldham JA, Woby SR. The association between cognitive factors, pain and disability in patients with idiopathic chronic neck pain. Disabil Rehabil. 2010;32:1758-1767.

51. Lobban F, Barrowclough C, Jones S. Assessing cognitive representations of mental health problems. I. The illness perception questionnaire for schizophrenia. Br J Clin Psychol. 2005;44(Pt 2):147-162.

52. Samarasekera SR, Helmstaedter C, Reuber M. Cognitive impairment in adults with epilepsy: the relationship between subjective and objective assessments of cognition. Epilepsy Behav. 2015;52(Pt A):9-13.

53. Ott CV, Bjertrup AJ, Jensen JH, et al. Screening for cognitive dysfunction in unipolar depression: validation and evaluation of objective and subjective tools. I Affect Disord. 2016;190:607-615.

54. O'Farrell E, Smith A, Collins B. Objective-subjective disparity in cancer-related cognitive impairment: does the use of change measures help reconcile the difference? PsychoOncology. 2017;26:1667-1674.

55. Rosti-Otajarvi E, Ruutiainen J, Huhtala H, Hamalainen P. Relationship between subjective and objective cognitive performance in multiple sclerosis. Acta Neurol Scand. 2014;130:319-327.

56. Coppieters I, De Pauw R, Kregel J, et al. Differences between women with traumatic and idiopathic chronic neck pain and women without neck pain: interrelationships among disability, cognitive deficits, and central sensitization. Phys Ther. 2017;97:338-353.

57. Plotek W, Lyskawa W, Kluzik A, et al. Evaluation of the Trail Making Test and interval timing as measures of cognition in healthy adults: comparisons by age, education, and gender. Med Sci Monit. 2014;20:173-181.

58. de Azeredo Passos VM, Giatti L, Bensenor I, et al. Education plays a greater role than age in cognitive test performance among participants of the Brazilian Longitudinal Study of Adult Health (ELSA-Brasil). BMC Neurol. 2015;15:191.

59. Harkness JA, Schoua-Glusberg AS Questionnaires in translation. In: Harkness JA, ed. Cross-Cultural Survey Equivalence. ZUMA-Nachrichten Spezial, 3. Mannheim, Germany: ZUMA; 1998: 87-126.

60. Karthikeyan G, Manoor U, Supe SS. Translation and validation of the questionnaire on current status of physiotherapy practice in the cancer rehabilitation. J Cancer Res Ther. 2015;11:29-36.

61. Moriarty O, McGuire BE, Finn DP. The effect of pain on cognitive function: a review of clinical and preclinical research. Prog Neurobiol. 2011;93:385-404.

62. Moriarty O, Finn DP. Cognition and pain. Curr Opin Support Palliat Care. 2014;8:130-136.

63. Tang NK, Goodchild CE, Salkovskis PM. Hybrid cognitive-behaviour therapy for individuals with insomnia and 
chronic pain: a pilot randomised controlled trial. Behav Res Ther. 2012;50:814-821.

64. Pinheiro MB, Ho KK, Ferreira ML, et al. Efficacy of a sleep quality intervention in people with low back pain: protocol for a feasibility randomized co-twin controlled trial. Twin Res Hum Genet. 2016;19:492-501.
65. Legault G, Clement A, Kenny GP, Hardcastle S, Keller N. Cognitive consequences of sleep deprivation, shiftwork, and heat exposure for underground miners. Appl Ergon. 2017;58:144-150. 